\title{
Modelling near-surface temperature conditions in high mountain environments: an appraisal
}

\author{
Roland Pape $^{1,2, *}$, Dirk Wundram ${ }^{1}$, Jörg Löffler ${ }^{1}$ \\ ${ }^{1}$ Department of Geography, University of Bonn, Meckenheimer Allee 166, 53115 Bonn, Germany \\ ${ }^{2}$ Department of Biology and Environmental Sciences, University of Oldenburg, PO Box, 26111 Oldenburg, Germany
}

\begin{abstract}
In response to the paucity of temperature data for high mountain environments at spatial and temporal resolutions reasonable for ecological modelling, this study evaluated both physically and statistically based modelling (or interpolation) of near-surface temperatures in a high mountain environment at sub-daily time scales and differing spatial scales. We placed emphasis on the selection of guiding environmental variables for temperature interpolation at a macro-scale, on a comparison of physically and statistically based modelling at meso- and micro-scale, and on a discussion of scaling issues. Geostatistical interpolation was found to perform very well at a macro-scale if additional topographic and atmospheric covariables - the latter provided by remote sensing - are considered. Physically based modelling performed best at a nano-scale, but revealed limits of spatial applicability due to limited input data. Statistical modelling based on multiple linear regression, however, showed results of intermediate accuracy throughout the spatial scales, providing encouraging evidence that we can find a simple approach to estimate near-surface temperature fields in high mountain environments. Attention to scaling issues proved to be important to achieve accurate results, though this was hampered by the starting point of the study: the lack of observational data at finer spatial scales.
\end{abstract}

KEY WORDS: Surface energy balance model · Spatial interpolation · Ecologically relevant temperatures $\cdot$ Scaling $\cdot$ Scandes

\section{INTRODUCTION}

Mountain environments are extremely sensitive to changes in environmental conditions, and thus to climatic change (Beniston et al. 1997, Pauli et al. 2001, Theurillat \& Guisan 2001, Dirnböck et al. 2003). For example, the distribution of plants is, to a major extent, determined by spatial variation in temperature, soil moisture conditions and snow cover (Gjærevoll 1990, Dahl 1998, Wielgolaski 1998, Moen 1999, Löffler 2005, Löffler \& Pape 2008) -3 environmental factors directly affected by climatic change. Studies on vegetation patterns, however, often rely on a single proxy variable-elevation-as a convenient way of representing these environmental factors (Whittaker 1978, Grytnes 2003). Obviously, regimes of both temperature and moisture are related to elevation due to the environmental lapse rate and the increase in precipitation with altitude, but these vary substantially in space and time (Rolland 2003). With such variation, the common practice of adjusting mean station temperatures to a reference altitude using solely lapse rates is likely to produce non-comparable and therefore misleading results (Barry 2008). Moreover, largescale patterns related to altitude or climatic regime (i.e. degree of continentality) are strongly modified by effects of local topography, and the latter can even be superimposed on the former (e.g. Löffler \& Pape 2004, Löffler et al. 2006). Consequently, Lookingbill \& Urban (2003) stress the necessity to use more descriptive means to characterize key ecological constraints directly affected by climatic change-i.e. temperature rather than elevation-in order to model future ecological processes. 
In order to be sufficiently accurate to capture detailed environmental patterns, models of ecosystem response need to be run at the meso- or micro-scale, where such patterns - which tend to level off at regional to global scales - cannot be ignored. Since the overall spatial performance of these models is essentially dependent on the accuracy of input data, climatic data also have to be provided at this spatial scale. However, obtaining these data at sufficient levels of accuracy is hampered by two logistical issues. (1) Since routine meteorological observations are available at discrete points in space, typically separated by a distance of 30 to $50 \mathrm{~km}$ or more, a spatial interpolation is necessary to produce data with a sufficient resolution. However, weather stations are particularly sparse in mountain regions, and tend to be located mainly at populated lower elevations (Barry 2008) - a fact that is likely to limit interpolation accuracy over mountainous regions. (2) Climate models are still particularly inaccurate at the micro-scale (Chen et al. 1999), since the required resolution is far below the typical grid-size even of the highest resolution numerical models (e.g. Rivington et al. 2008). Since numerous climatological details of mountain environments are simply overlooked by common climate models, it has consequently been recognised that comprehensive physically based land-surface schemes are needed in atmospheric models to adequately simulate near-surface exchanges of heat, moisture and momentum (e.g. Saunders et al. 1999a,b). However, the required input data for these schemes, especially vegetation physiological parameters and soil characteristics, are commonly unavailable at larger spatial scales in remote mountainous regions. Thus, there has recently been a large number of environment-related studies (often using remotely sensed data) on (geo)statistical approaches for interpolating climatic parameters at high spatio-temporal resolution (e.g. Lookingbill \& Urban 2003, Joly et al. 2003, Chung \& Yun 2004, Chung et al. 2006, Stahl et al. 2006, Joly \& Brossard 2007).

The present paper evaluates both physically and statistically based modelling and interpolation of nearsurface temperatures in a high mountain environment at sub-daily time scales and differing spatial scales with the following specific objectives:

(1) to determine environmental variables that aid (guide) the spatial interpolation of temperatures at different scales;

(2) to compare the performance of physically based modelling and statistically based interpolation;

(3) to determine whether there are scale-limits in modelling and interpolation approaches, and address such scaling issues in order to develop an improved approach.

\section{DATA AND METHODS}

\subsection{Data}

2.1.1. Study areas

The study was conducted in central Norway along $62^{\circ} \mathrm{N}$, representing the macro-scale (Fig. 1A). The mountain chain of the Scandes reaches $2469 \mathrm{~m}$ a.s.l. (above sea level) elevation in this region, resulting in a clearly defined oceanic-continental gradient between the western and eastern slopes of the mountain chain. Within the frame of a long-term ecological project (Löffler 2002, 2003, Löffler \& Finch 2005) 2 meso-scaled areas were chosen to represent the climatic differences. Geiranger $\left(62^{\circ} 03^{\prime} \mathrm{N}, 7^{\circ} 15^{\prime} \mathrm{E}\right.$; Fig. 1B) within the inner fjords region of western Norway is climatically characterized as sub-oceanic with annual precipitation of 1500 to $2000 \mathrm{~mm}$ in the valleys (Moen 1999). A more continental climate is found only $150 \mathrm{~km}$ east of the

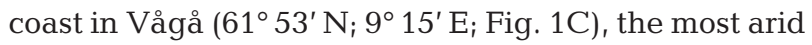
area in Norway Moen (1999), with annual precipitation of about 300 to $400 \mathrm{~mm}$ in the valleys. The alpine ecological zone extends from the tree-line at $\sim 840$ to $880 \mathrm{~m}$ a.s.l. (Geiranger) or 1000 to $1050 \mathrm{~m}$ a.s.l. (Vågå), to the highest peaks at $1775 \mathrm{~m}$ a.s.l. in Geiranger and $1618 \mathrm{~m}$ a.s.l. in Vågå. It comprises the low-alpine zone characterized by dwarf-shrub and lichen heaths, the middlealpine zone dominated by chionophobous lichens and graminoid species; and in Geiranger, also the highalpine zone with glaciated areas. Figs. $1 \mathrm{~B}$ and $1 \mathrm{C}$ illustrate the contrast in topography of the Geiranger and Vågå areas (steeply and gently sloping, respectively). In both areas, 2 micro-scaled catchments were chosen to represent the low- and middle-alpine zones; the Våga area in the low-alpine (Fig. 1D,E) was chosen for exemplary micro-scaled modelling.

\subsubsection{Climatological data}

The climatological data used for this study were obtained from 45 weather stations at locations shown in Fig. 1A. The stations are operated by the Norwegian Meteorological Service (38 stations, Det norske meteorologiske institutt, DNMI, data available at www. eklima.no), the Norwegian Geological Service in the Geiranger area (3 stations, Norges geologiske undersøkelse, NGU) and our own in the Geiranger and Vågå area (4 stations, Geographisches Institut der Universität Bonn, GIUB). In addition to 1 weather station, 4 data loggers are located in the micro-scaled catchment representing main topographic positions (Fig. 1D). The data comprised air temperatures at $2 \mathrm{~m}$ height $\left(\mathrm{T}_{\mathrm{A}}\right)$ for 2004 as daily maxima $\left(\mathrm{T}_{\mathrm{AMX}}\right)$ and minima $\left(\mathrm{T}_{\mathrm{AMN}}\right)$ for the DNMI 


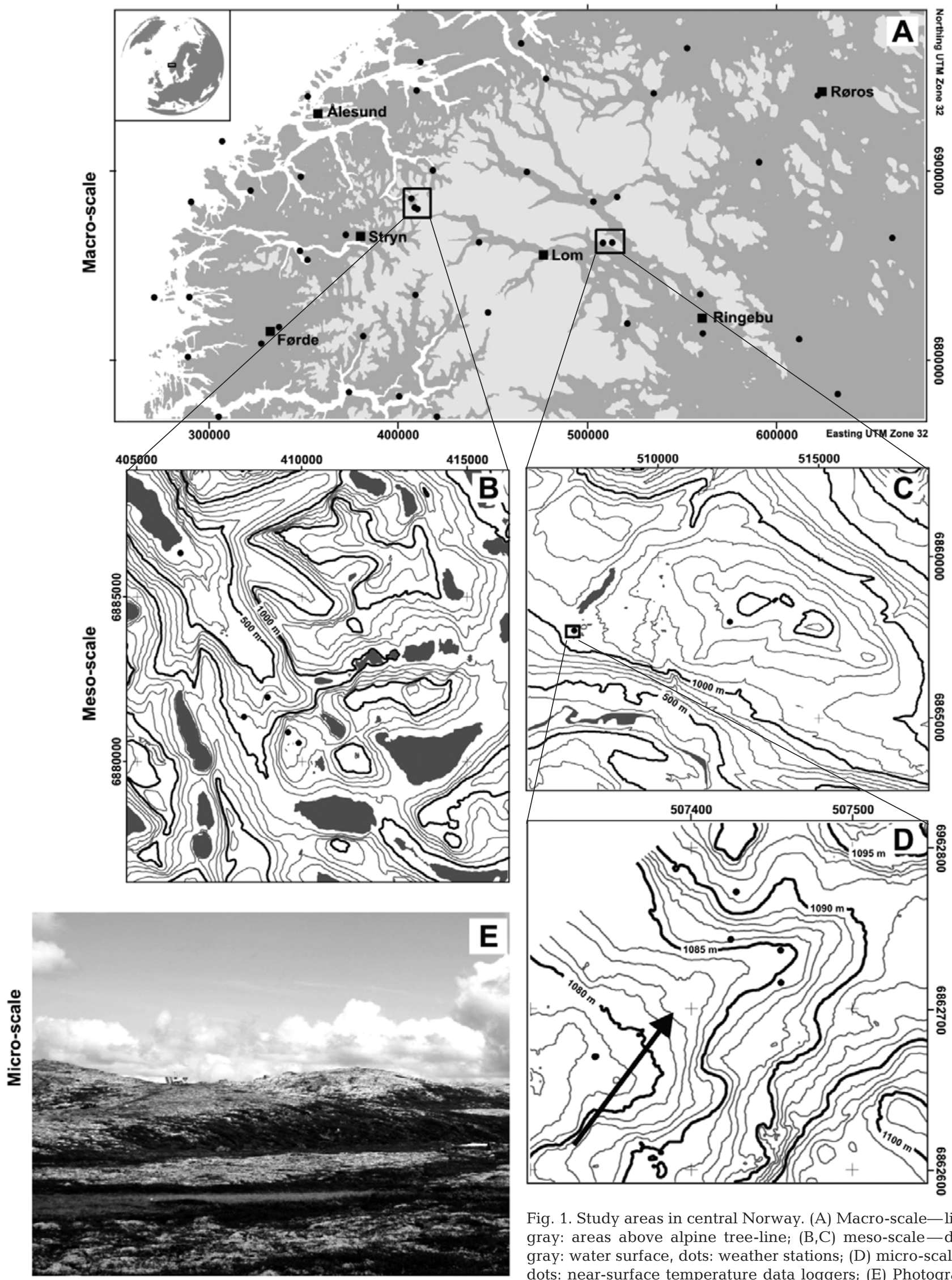

Fig. 1. Study areas in central Norway. (A) Macro-scale-light gray: areas above alpine tree-line; $(\mathrm{B}, \mathrm{C})$ meso-scale-dark gray: water surface, dots: weather stations; (D) micro-scaledots: near-surface temperature data loggers; (E) Photograph depicting part of area shown in (D) (arrow in [D] shows direction of view), giving an impression of the fine-scaled variability 
stations, 1 and $2 \mathrm{~h}$ means (GIUB and NGU, respectively). The data loggers record soil and air temperatures as hourly means at $-15,-1$ and $+15 \mathrm{~cm}$ distance from the soil surface, hereafter referred to as $\mathrm{T}_{\mathrm{S}}, \mathrm{T}_{\mathrm{SFC}}$, and $\mathrm{T}_{\mathrm{A} 15}$, respectively. These temperatures are also recorded at the GIUB stations, along with the additional measurements of global short-wave radiation $(\mathrm{K} \downarrow)$, precipitation, relative humidity, wind speed at $2 \mathrm{~m}$ above ground $(u)$ and wind direction. To ensure data quality as well as comparability of the three different networks, prior to further analysis, all data were checked with regard to data range, temporal change, plausibility, and synchronicity, according to methods described by Rissanen et al. (2000). In addition, absolute deviations between the NGU and GIUB networks were compared at 2 neighbouring stations; no deviations $>1 \mathrm{~K}$ were detected.

\subsubsection{Remote sensing data}

To complement the ground-based observations, spatial data on land surface temperature (LST) with a resolution of $1 \mathrm{~km}$ were obtained for each day/night in 2004 from thermal infrared (TIR) MODIS (Moderate Resolution Imaging Spectroradiometer) data. Additional data on LST at $60 \mathrm{~m}$ resolution were available for 10 August 2004, originating from an overflight of Landsat 7 Enhanced Thematic Mapper (ETM) at 10:36 h. Ancillary data on daily (for some MODIS products: $8 \mathrm{~d}$ period) cloud cover, snow cover, surface albedo, and normalized difference vegetation index (NDVI) were also derived from the MODIS and Landsat ETM data. For the micro-scaled catchment, high-resolution $(0.1 \mathrm{~m})$ 3-band (red-green-blue, RGB) images and TIR aerial photos based on kite aerial photography (Wundram \& Löffler 2008) were available for 14:30 h on 4 October 2004. Spatial patterns of vegetation at meso- and micro-scale were derived by maximum likelihood classification based on ground truthing plots.

\subsubsection{Topographic data}

For the macro-scale, a digital elevation model (DEM) with a spatial resolution of $500 \mathrm{~m}$ was derived from the Global 30 Arc-Second Elevation Data Set (GTOPO30), projected to Universal Transverse Mercator (UTM) Zone 32, resulting in a spatial resolution of $500 \mathrm{~m}$. At meso-scale, a DEM with a resolution of $30 \mathrm{~m}$ (to match the Landsat ETM scene) is based on topographic maps of the Norwegian Mapping Authority at scale 1:50 000. For the micro-scale, a DEM at $0.1 \mathrm{~m}$ resolution was derived by photogrammetry from kite aerial photos in conjunction with stadia surveying of ground control points (Wundram \& Löffler 2008).

\subsection{Methods}

\subsubsection{Model scales}

Based on the abovementioned data (Sections 2.1.2 to 2.1.4) available for further analyses, interpolation and modelling of temperatures involved 4 different spatial scales: (1) the macro-scale comprises an area of roughly $88000 \mathrm{~km}^{2}$ with a grid cell resolution of $500 \mathrm{~m}$; (2) at meso-scale there are 2 areas of about 100 and $80 \mathrm{~km}^{2}$, respectively, with a resolution of $30 \mathrm{~m}$; (3) at microscale there is an area of $0.04 \mathrm{~km}^{2}$ with a resolution of $0.1 \mathrm{~m}^{2}$; and (4) the nano-scale refers to point specific approaches without spatial dimensions.

\subsubsection{Geostatistical interpolation of $\mathrm{T}_{\mathrm{AMX}}$ and $\mathrm{T}_{\mathrm{AMN}}$}

Over extensive areas like our macro-scaled region, deriving spatially distributed data using processbased approaches may be impractical for reasons of computational and theoretical complexity or the unavailability of data. Grid-based interpolation was used instead, adopting a 'middle ground' between databased geostatistical interpolation and process-based meteorological modelling (Jarvis \& Stuart 2001). This approach is achieved by spatially interpolating temperature at the macro-scale using indices developed from atmospheric, topographic and land cover data that we hypothesized to influence the climatic conditions.

A set of 16 potential guiding variables (Table 1) was derived, accounting in particular for topographic effects that might affect temperature patterns: easting and northing describe the $x, y$-coordinates in the UTM zone 32 grid; potential solar radiation was calculated for each time step considered in further analyses using

Table 1. Potential guiding variables for temperature interpolation

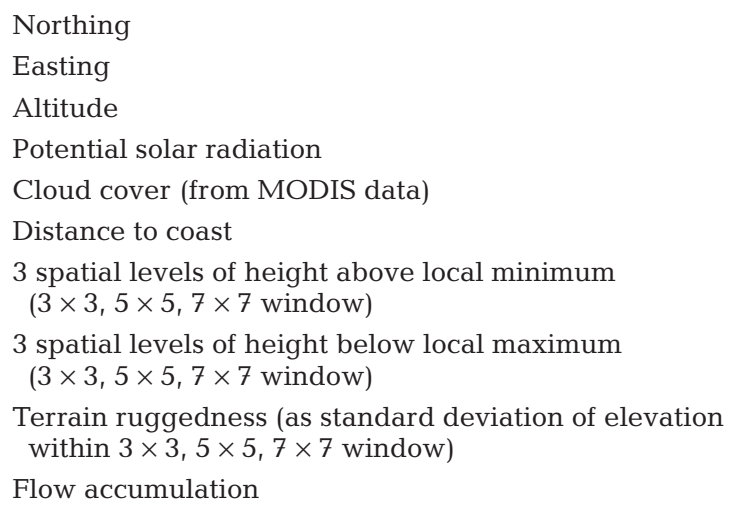

Terrain ruggedness (as standard deviation of elevation within $3 \times 3,5 \times 5,7 \times 7$ window)

Flow accumulation 
the r.sun module of GRASS (geographic information system [GIS] software) that also accounts for topographic masks (Hofierka \& Suri 2002); and height above local minimum (below local maximum) was calculated in a moving window of $3 \times 3,5 \times 5$ and $7 \times 7$ grid cells as the difference between elevation of the centre cell and lowest (highest) elevation in the surroundings. Terrain ruggedness was calculated as the standard deviation of elevation for the same window sizes. To address cold air drainage and accumulation, an approach commonly used in hydrology was adopted: flow accumulation was calculated using the r.terraflow module of GRASS. In a first step, the power of explanation for each single variable with regard to temperature patterns was tested separately for $\mathrm{T}_{\mathrm{AMX}}$ and $\mathrm{T}_{\mathrm{AMN}}$ using stepwise linear regression with collinearity diagnostics for 52 independent days in 2004. The 5 variables that were most included in the regressions and had the highest partial correlations were then chosen as environmental guiding variables for the actual interpolation approach. Second order partial thin-plate splines were used for interpolation, with easting and northing as independent variables and the environmental guiding variables as multiple linear covariates (Hutchinson 1991, Jarvis \& Stuart 2001). A cross-validation estimate of error within the resulting temperature maps was achieved by jackknifing at known data points. The resulting error estimation was differentiated for alpine and non-alpine data points used for jackknifing, since differences in sensitivity between these 2 groups have to be expected: 1 station left out within a sparse station record is likely to produce a more pronounced error than within a comparably dense station record.

\subsubsection{Physically based LST modelling}

Due to the limited amount of input data available compared to the input data needed for land surface schemes, we chose a rather simple energy balance approach developed for such data-limited applications (Pape \& Löffler 2004). The model estimates surface temperatures by iterative solution of the energy balance constituted by net radiation $\left(Q^{*}\right)$ on the one hand and sensible, latent and ground heat fluxes (H, LE and $\mathrm{G}_{0}$ ) on the other. Originally developed for point applications, it was implemented in a GIS for micro- and meso-scale applications here; it does not, however, account for lateral effects: the lack of spatial information on soil characteristics and plant physiological parameters forced further simplifications compared to the original settings of the model to make it spatially applicable. Instead of an analytical solution, the $\mathrm{G}_{0}$ was parameterized as a ratio of net radiation (e.g. de
Bruin \& Holtslag 1982, Kustas \& Daughtry 1990) leading to $\mathrm{G}_{0}=a Q^{*}$, with $a$ chosen as (i) a constant value of 0.15 , and (ii) $-0.27 \mathrm{NDVI}+0.39$, to account for its dependence on vegetation cover (Jacobsen \& Hansen 1999). The factor $a$ is different for daytime and nighttime, because during daytime the energy provided by $Q^{*}$ is shared between $\mathrm{G}_{0}$ and the turbulent heat fluxes, while these are nearly negligible during night-time and $\mathrm{G}_{0}$ makes up the largest part of $Q^{*}$. Thus, the modelling approach was restricted to daytime.

Evapotranspiration was estimated by the modified Priestley-Taylor concept (Priestley \& Taylor 1972, van Ulden \& Holtslag 1985, de Rooy \& Holtslag 1998) instead of the original Penman-Monteith approach (Monteith 1981) in order to avoid the estimation of aerodynamic and surface resistances.

The resulting set of equations is as follows, where the energy balance is given by

$$
Q^{*}=\mathrm{H}+\mathrm{LE}+\mathrm{G}_{0}
$$

with net radiation according to de Bruin \& Holtslag (1982) estimated by

$$
\begin{aligned}
& Q^{*}=\mathrm{K} \downarrow-\mathrm{K} \uparrow+\mathrm{L} \downarrow-\mathrm{L} \uparrow= \\
& (1-A) \mathrm{K} \downarrow+5.31 \times 10^{-13} \mathrm{~T}_{\mathrm{A}}{ }^{6}-0.95 \sigma \mathrm{T}_{0}{ }^{4}
\end{aligned}
$$

where $\mathrm{K}$ and $\mathrm{L}$ denote short- and longwave radiation, respectively ( $\downarrow$ : incoming; $\uparrow$ : outgoing), $A$ denotes the albedo, $\sigma$ the Stefan-Boltzmann constant $\left[\mathrm{W} \mathrm{m} \mathrm{m}^{-2} \mathrm{~K}^{-1}\right]$ and $\mathrm{T}_{0}$ the temperature at the effective surface taken as LST. Both temperatures are given as absolute temperatures [K]. In our case, $\mathrm{K} \downarrow$ was based on reference observations spatially corrected for topography (Oke 2001) while $A$ was estimated from remote sensing data. The air temperature $\mathrm{T}_{\mathrm{A}}$ was at meso-scale application taken from the abovementioned interpolation approach of $\mathrm{T}_{\mathrm{AMX}}$ (see Section 2.2.2.) and at micro- and nanoscale applications from hourly measurements at 1 site within the area, but corrected for the higher resolution-topography at finer scales using actual temperature lapse rates derived from measurements.

$\mathrm{H}$ is estimated using an aerodynamic approach (Oke 2001):

$$
\mathrm{H}=-C_{\mathrm{a}} \mathrm{k}^{2}\left\{u\left(\mathrm{~T}_{\mathrm{A}}-\mathrm{T}_{0}\right) /\left[\ln \left(z_{\mathrm{A}} / z_{0}\right)\right]^{2}\right\}\left(\phi_{\mathrm{M}} \phi_{\mathrm{H}}\right)^{-1}
$$

where $C_{\mathrm{a}}$ is the heat capacity of air $\left(\mathrm{J} \mathrm{m}^{-3} \mathrm{~K}^{-1}\right), \mathrm{k}$ is the von Karman's constant $(0.41 \mathrm{~m}), u$ is the windspeed at $2 \mathrm{~m}, z_{\mathrm{A}}$ is the height of air temperature measurement $(2 \mathrm{~m}), z_{0}$ is the surface roughness length $(\mathrm{m})$, and finally $\left(\phi_{\mathrm{M}} \phi_{\mathrm{H}}\right)^{-1}$ is a stability correction dependent on the Richardson number Ri during stable cases $(\mathrm{Ri}>0)$ by

$$
\left(\phi_{\mathrm{M}} \phi_{\mathrm{H}}\right)^{-1}=(1-5 \mathrm{Ri})^{2}
$$

and during unstable cases $(\mathrm{Ri}<0)$ by

$$
\left(\phi_{\mathrm{M}} \phi_{\mathrm{H}}\right)^{-1}=(1-16 \mathrm{Ri})^{3 / 4}
$$


The Richardson number itself is estimated by

$$
\mathrm{Ri}=g / \mathrm{T}\left[\left(\mathrm{T}_{\mathrm{A}}-\mathrm{T}_{0}\right)\left(z_{\mathrm{A}}-z_{0}\right)\right] / u^{2}
$$

where $g$ is the acceleration due to gravity $\left(\mathrm{m} \mathrm{s}^{-2}\right)$ and $\mathrm{T}$ without subscript is the mean of $\mathrm{T}_{\mathrm{A}}$ and $\mathrm{T}_{0}$.

Since this approach requires a spatial wind field, the distribution of wind speed within the area was approximated using a simple approach proposed by Böhner (2004): the relative increase or decrease in wind speed reflects specific distance-related effects of orography due to wind- and lee exposure. For eight discrete sectors of wind direction ( $N, N E, E, \ldots)$ a coefficient of wind speed reduction is derived that enables a spatial quantification of variations in wind speed determined by orography, if observations at one reference station are provided. The coefficient $(W)$ comprised of slope angle functions upwind (subscript u) and downwind (subscript d), given by

$$
\begin{aligned}
& W_{\mathrm{u}}=\sum_{i=1}^{n} 1 / d_{\mathrm{uhi}} \tan ^{-1}\left(d_{\mathrm{uzi}} / d_{\mathrm{uhi}}^{0.5}\right) / \sum_{i=1}^{n} 1 / d_{\mathrm{uh} i}+ \\
& \sum_{i=1}^{n} 1 / d_{\mathrm{dh} i} \tan ^{-1}\left(d_{\mathrm{dzi}} / d_{\mathrm{dh} i}^{0.5}\right) / \sum_{i=1}^{n} 1 / d_{\mathrm{dh} i} \\
& W_{\mathrm{d}}=\sum_{i=1}^{n} 1 / \ln \left(d_{\mathrm{dh} i}\right) \tan ^{-1}\left(d_{\mathrm{dzi}} / d_{\mathrm{dh} i}^{0.5}\right) / \sum_{i=1}^{n} 1 / \ln \left(d_{\mathrm{dh} i}\right)
\end{aligned}
$$

where $d_{\mathrm{h} i}$ is the distance to raster cell $i$, and $d_{\mathrm{z} i}$ is the difference in height to raster cell $i$. The corresponding parameter functions are given by

$$
\begin{aligned}
& \text { luv }=1+\ln \left(1+W_{\mathrm{u}}\right) \text { if } W_{\mathrm{u}}>0 \\
& \text { luv }=\left[1+\ln \left(1-W_{\mathrm{u}}\right)\right]^{-1} \text { if } W_{\mathrm{u}}<0 \\
& \text { lee }=\left[1+\ln \left(1+W_{\mathrm{d}}\right)\right]^{0.5} \text { if } W_{\mathrm{d}}>0 \\
& \text { lee }=\left[1+\ln \left(1-W_{\mathrm{d}}\right)\right]^{-0.5} \text { if } W_{\mathrm{d}}<0
\end{aligned}
$$

Finally, the wind speed $u$ is calculated using the reference observation $u_{\mathrm{r}}$ by

$$
u=u_{\mathrm{r}}(\mathrm{luv} \times \mathrm{lee})^{0.25}
$$

Since it is known that spatial wind fields in mountainous terrain are highly difficult to estimate, results were compared to hand-held measurements.

LE is calculated, according to the modified PriestleyTaylor concept, by

$$
\mathrm{LE}=\alpha s\left(Q^{*}-\mathrm{G}_{0}\right) /(s+\gamma)+\beta
$$

where $\alpha$ is an empiral constant ranging from 0 (for very dry conditions when no evaporation occurs) to 1.26 (for saturated conditions), $s$ is the slope of saturation vapour versus temperature curve $\left[\mathrm{Pa} \mathrm{K} \mathrm{K}^{-1}\right], \gamma$ is the psychrometric constant $\left[\mathrm{Pa} \mathrm{K} \mathrm{K}^{-1}\right]$, and $\beta$ is an empirical constant of $20 \mathrm{~W} \mathrm{~m}^{-2}$. The value of $\alpha$ was chosen depending on the vegetation type according to literature. Results from studies in the Arctic indicate that the value for $\alpha$ in dry regions characterized by sedge tussocks, mosses, lichens, and shrubs is at or near 1.00 (Rouse \& Stewart 1972, Stewart \& Rouse 1976, Rouse et al. 1977). In wet areas characterized by wet sedge tundra and small ponds, a number of studies have indicated that appropriate $\alpha$ values should be $\geq 1.26$ (Stewart \& Rouse 1976, Roulet \& Woo 1986, Bello \& Smith 1990, Rovansek et al. 1996).

As already mentioned, $\mathrm{G}_{0}$ is parameterized in 2 forms as

$$
\mathrm{G}_{0}=0.15 Q^{*}
$$

and

$$
\mathrm{G}_{0}=(-0.27 \mathrm{NDVI}+0.39) Q^{*}
$$

where NDVI is derived from the Landsat ETM scene. This set of equations is then solved for LST using an iterative approach. Depending on the spatial scale regarded, the set of equations is solved on an hourly basis for nano- and micro-scales and once a day for meso-scale. In this study, the performance of the model was tested at nano-, micro-, and meso-scales against measurements of LST. Consequently, the model was run at the specific grid resolutions (except at nano-scale) that corresponded with grid-based input data in order to enable a comparison of the results to grid based observations at the same spatial resolution.

\subsubsection{Statistically-based LST modelling}

Similar to the interpolation of air temperatures, we sought to adopt a physical basis for this modelling approach. Independent environmental variables were chosen with respect to their relevance for surface temperatures and comprised (1) $\mathrm{K} \downarrow$ based on reference observations but spatially corrected for topography (Oke 2001), (2) albedo, (3) NDVI, and (4) the $\mathrm{G}_{0} / Q^{*}$ ratio as derived from remote sensing data. Furthermore, (5) the Priestley-Taylor coefficient $\alpha$ based on vegetation types, and (6) the topographic wetness index (TWI) were treated as surrogates for soil moisture conditions. Finally, (7) the spatial wind field as described above, and (8) interpolated air temperatures (corrected for the actual height above sea-level) were considered.

A multiple linear regression model using stepwise selection routines was established at micro- and meso-scale, treating LST (derived from remote sensing data for August 10, 2004 and October 4, 2004) as the dependent variable. The dataset was split randomly to use $1 / 3$ for model building and $2 / 3$ for model validation. Moreover, the spatial transferability of these empirical models was tested by applying the model of the Geiranger area in Vågå and vice versa. 


\section{RESULTS}

\subsection{Geostatistical interpolation of $T_{A M X}$ and $T_{A M N}$}

Regarding the selection of the best guiding variables for interpolation of daily air temperatures, we detected a differentiation between maximum and minimum temperatures. (In the following, corresponding signs of correlation are given in brackets.) Maximum temperatures were best described using elevation $(-)$, cloud cover (-) and terrain ruggedness in a $5 \times 5$ window $(+)$ besides northing and easting. Minimum temperatures also showed a dependence on elevation (-), cloud cover (+), northing, and easting, but additionally on distance to coast ( - ) and height above local minimum at a $3 \times 3$ window (+). These variables were chosen as guiding variables for the further interpolation process based on partial thin-plate splines. Resulting temperature maps are exemplified for two high pressure situations in Fig. 2, with a typical winterly temperature inversion on January 17, 2004 and a clear sky summer condition on July 31, 2004. The oceanic-continental differentiation is clearly visible. The overall performance of the interpolation approach was tested using cross-validation estimates of error computed by jackknifing. These error estimates are visualized by the boxplots in Fig. 2. Interpolation of $\mathrm{T}_{\mathrm{AMN}}$ yields in general slightly better results than the interpolation of $\mathrm{T}_{\mathrm{AMX}}$, for which, (in non-alpine areas in the majority of cases) the error falls in the range of -2.2 to $2.8 \mathrm{~K}$. The error range of -3 to $3.6 \mathrm{~K}$ for the interpolation of $\mathrm{T}_{\mathrm{AMX}}$ indicates a decrease in accuracy with regard to alpine areas.

\subsection{Physically based LST modelling}

The physically based modelling approach of surface temperatures was applied from nano- to meso-scale. The results were validated against independent mea-
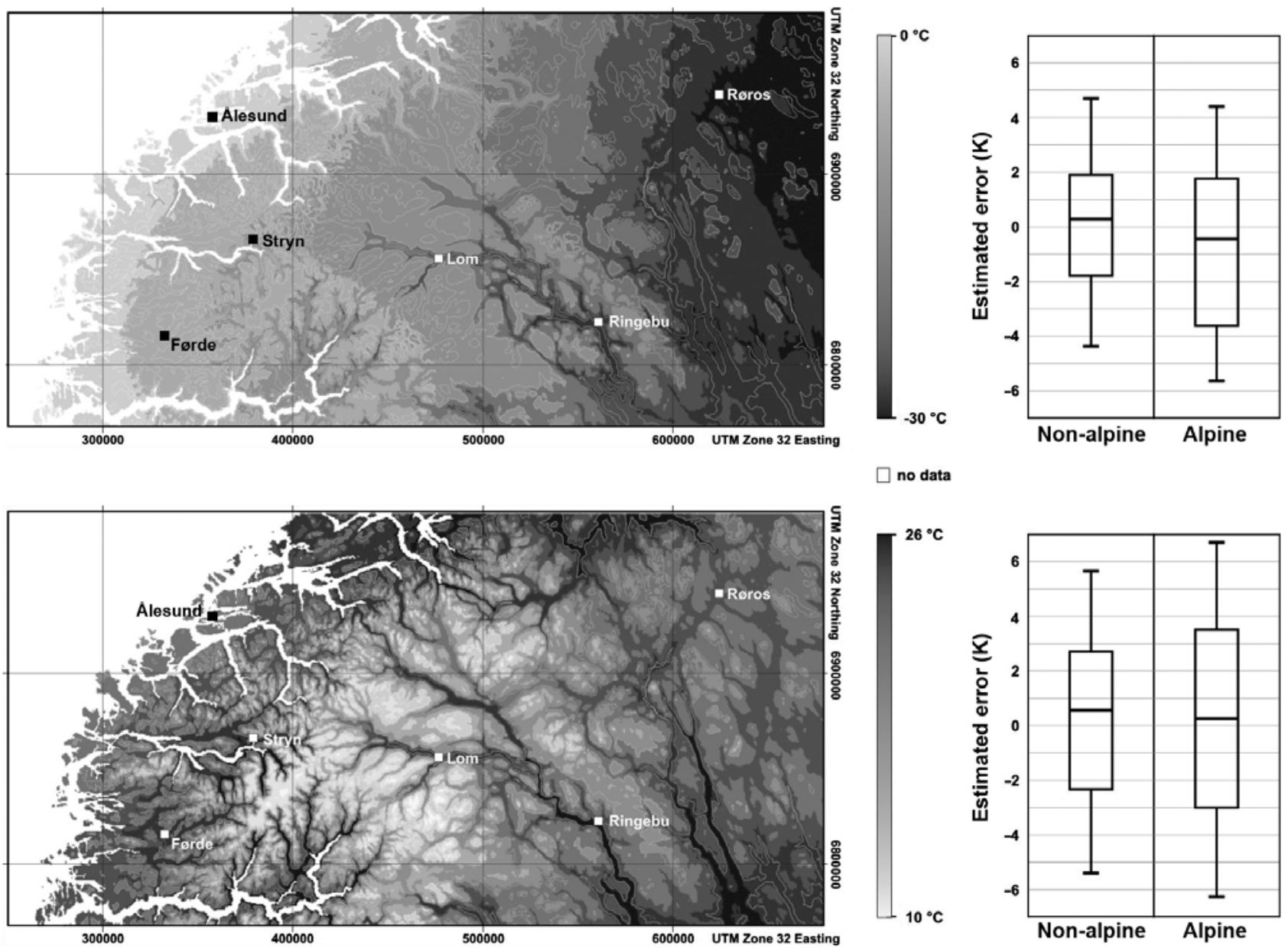

Fig. 2. Temperature interpolation based on partial thin-plate splines, exemplified for (a) $\mathrm{T}_{\mathrm{AMN}}$ on January 17,2004 and (b) $\mathrm{T}_{\mathrm{AMX}}$ on July 31, 2004. Boxplots show overall performance based on jackknifing for (c) $\mathrm{T}_{\mathrm{AMN}}$ and (d) $\mathrm{T}_{\mathrm{AMX}}$ at 53 independent days in 2004 

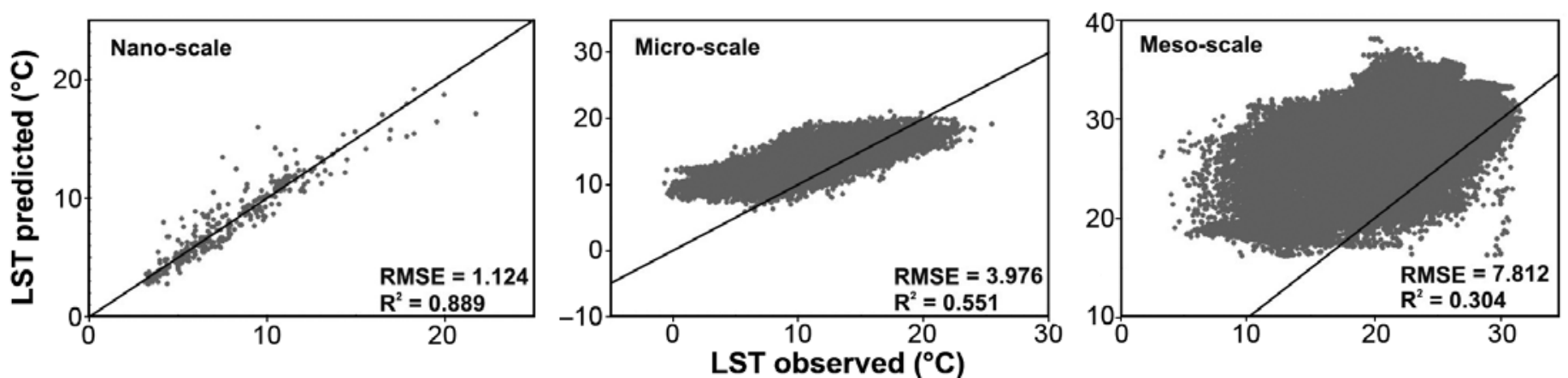

Fig. 3. Correlation biplots of observed vs. predicted land-surface temperature (LST) at different spatial scales estimated by the physically based modelling approach. Solid line: $y=x$ function

surements at nano-scale-i.e. measured LST by data loggers, and spatial information about LST by TIR aerial photographs at micro-scale as well as by TIR Landsat ETM data at meso-scale. A strong decline in accuracy and ability to predict LST while increasing the spatial extent is obvious from the correlation biplots given in Fig. 3. The model performs very well at nanoscale $\left(\mathrm{RMSE}=1.124, \mathrm{R}^{2}=0.889\right.$ ), but tends to overestimate low temperatures and to underestimate high temperatures at micro-scale, resulting in an RMSE that approaches 4 and a lower $\mathrm{R}^{2}$ of 0.551 . At meso-scale, the model mostly overestimates temperatures accompanied with a large scatter, resulting in poor values for RMSE and $\mathrm{R}^{2}$ (7.812 and 0.304 , respectively).

\subsection{Statistically based LST modelling}

Statistically based modelling has been applied from micro-scale to meso-scale. The independent variables chosen by the automatic stepwise selection routine are consistent throughout the different scales and comprise $\mathrm{K} \downarrow$, the $\mathrm{G}_{0}: Q^{*}$ ratio, and TWI, with $\mathrm{K} \downarrow$ showing the highest partial correlation coefficients ranging from 0.670 to 0.752 . Consequently, the full models are able to explain between 51 and $68 \%$ of the spatial temperature variance with a RMSE ranging from 2.2 to $2.8 \mathrm{~K}$. The performance of the model at micro- and meso-scale is shown as a correlation biplot in Fig. 4. However, the accuracy of the models diminished when transferred to another study area (Geiranger), as shown by the biplot to the far right in Fig. 4, indicating their limited validity.

\section{DISCUSSION}

The proper choice of environmental guiding variables for temperature interpolation is an important step assuring the quality of temperature fields produced; this step is essential for further representative climatological or ecological modelling (e.g. Jarvis \& Stuart 2001, Monestiez et al. 2001, Lookingbill \& Urban 2003). This is even more important when regarding interpolation of daily temperature maxima and minima instead of e.g. monthly means, since data at higher temporal resolution are expected to reflect more complex relationships that level off at greater
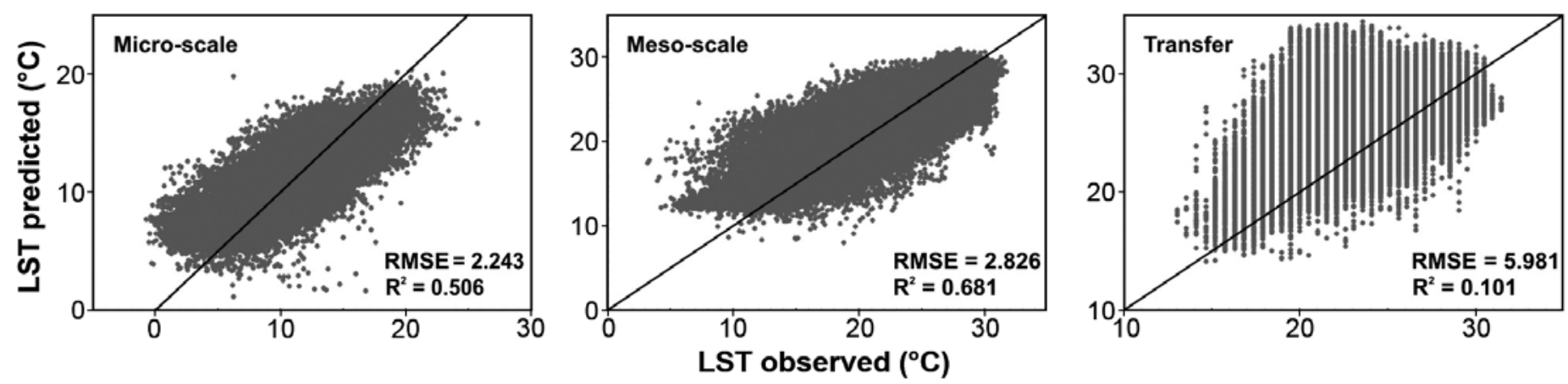

Fig. 4. Correlation biplots of observed vs. statistically predicted land-surface temperature (LST) at micro- and meso-scale. The biplot to the far right shows the limited performance of the meso-scale model transferred from eastern to western Norway. Solid line: $y=x$ function 
time scales (Lookingbill \& Urban 2003, Chung \& Yun 2004). However, it is very important to consider these extremes, as done in an increasing number of studies (e.g. Chung et al. 2006, Mostovoy et al. 2006), since they are important ecological measures (e.g. Körner 2003). We found a differentiation between variables important for temperature maxima and minima, in agreement with previous results (e.g. Jarvis \& Stuart 2001). Topography proved to be less important for $\mathrm{T}_{\mathrm{AMX}}$ than for $\mathrm{T}_{\mathrm{AMN}}$, reflecting the effect of cold air drainage on minimum temperatures. Distance to coastline was found to be another important variable determining $\mathrm{T}_{\mathrm{AMN}}$, as it mirrors the gradient in continentality not represented by the easting variable due to the fjord-shaped coastline. For both $\mathrm{T}_{\mathrm{AMX}}$ and $\mathrm{T}_{\mathrm{AMN}}$, cloud cover as derived from remote sensing data (MODIS) proved to be important, as it determines the radiation balance. This suggests that temperature interpolation can be enhanced by using atmospheric data provided by remote sensing. Mostovoy et al. (2006) already used MODIS-derived LST to aid interpolation of air temperatures. However, their approach is restricted to clearsky conditions and hence of limited applicability in mountain regions characterized by a high degree of cloudiness. Using the derived guiding variables in a partial thin-plate spline approach for the interpolation of $\mathrm{T}_{\mathrm{AMX}}$ and $\mathrm{T}_{\mathrm{AMN}}$, we achieved a good agreement between interpolated and observed temperatures with an error range of approximately $\pm 2 \mathrm{~K}$ in the lowlands in most cases, but increasing for alpine areas. However, the error range of -3 to $3.6 \mathrm{~K}$ is still relatively small compared to e.g. adabatic lapse rate-based interpolation (data not shown), and thus our approach is also suitable for mountainous regions.

It has been shown that surface temperatures in high mountain environments tend to be decoupled from air temperatures at common screen-level, i.e. variations in LST are not reflected by air temperature patterns (Löffler \& Pape 2004). Thus, the representativeness of screen-level measurements for ecological applications in high mountain environments needs to be critically questioned (see e.g. Leser 1997). As a consequence, the interpolated air temperatures served in a further step as input for a physically based modelling of surface temperatures.

The model was applied throughout different spatial scales, from nano-scale to meso-scale and validated against measured or remote sensing-derived LST. Despite several simplifications of the model that were necessary for spatial application in regions with limited data availability, the performance at nano-scale was very good $\left(\mathrm{RMSE}=1.124, \mathrm{R}^{2}=0.889\right.$ ). However, starting at micro-scale and continuing meso-scale, the performance declined drastically until the RMSE was 7.8, probably resolving limitations of the parameteriza- tions used. For example, the wind field is parameterized rather simply, but we were also able to validate the approach based on our own data (not shown). The Priestley-Taylor concept utilized for estimating LE has been shown to provide acceptable accuracy for predicting daily evaporation in Arctic ecosystems if the value of the $\alpha$ coefficient is known (Rouse et al. 1977). However, $\alpha$ values have been shown to vary over time and space related to changes in vegetation type and state, soil moisture, and meteorological conditions (Rovansek et al. 1996, Mendez et al. 1998, Engstrom et al. 2002). Our approach of assuming constant values for $\alpha$ taken from literature and depending solely on vegetation type may, therefore, have caused erroneous results. Further inaccuracy might arise from parameterization of $\mathrm{G}_{0}$. Liebethal \& Foken (2007) found-in their evaluation of 6 parameterizations - that all of them had the potential to model results that match observed ones very well, but only if all conditions and restrictions of the respective approaches were taken into account. For the linear approach used in our study, they found a pronounced variability of the factor $a$ in space and time related to soil moisture and vegetation height. We yielded a better performance of the model when a was expressed as function of NDVI, rather than treated as a constant (data not shown). However, the same NDVI function used here to express a was found by Jacobsen \& Hansen (1999) for comparable vegetation types, but might not-due to its empirical character-be easily transferred to other regions. Moreover, the NDVI might not reflect differences in vegetation height and soil moisture conditions adequately, although a high correlation between NDVI and moisture status was found by Ostendorf \& Reynolds (1993). These drawbacks probably explain the decline in model performance when applied at larger spatial extents, indicating a spatial limit for reasonable applicability. Consequently, our findings underline the importance of appropriate parameterizations that need to be developed for high mountain regions, since existing parameterizations could not easily be transferred from the environments they have originally been developed for.

Due to the complexity of physically based modelling approaches, we also tested the performance of a simpler approach based on statistics, following recent trends in research (e.g. Chung et al. 2006, Stahl et al. 2006, Joly \& Brossard 2007). As a result, up to $68 \%$ of the spatial variance in surface temperature could be related to irradiance, $\mathrm{G}_{0} / Q^{*}$-ratio as a function of NDVI, and TWI. It is possible that we would have achieved even better results if we had used an alternative measure of soil moisture conditions to the TWI (which has been proven to reflect soil moisture better for wet than for dry or intermediate conditions; Sulebak et al. 2000). However, the approach we used per- 
formed similarly across the different spatial scales, suggesting that statistical approaches are an adequate means of modelling temperature fields in high mountain environments, even if they fall down on their limited transferability to other regions.

The statistical approach revealed other important facts. Neither the Priestley-Taylor coefficient $\alpha$, the wind-field, nor the interpolated air temperature at a height of $2 \mathrm{~m}$ above ground contributed statistically significantly to the variability of LST. The first 2 facts might be attributed to a wrong parameterization, also responsible for the limited performance of the physically based modelling approach. More interesting is the apparent non-significance of air temperature: this may be related to the already mentioned decoupling of airand surface temperatures, but it is even more likely that it reveals scaling issues, leading to questions of the extent to which modelling or interpolation approaches can be applied reasonably to other spatial scales. It is questionable as to whether air temperatures interpolated at macro-scale can be downscaled using only elevation as corrector (as done in the present study, and also by Wang et al. 2006), especially when regarding a meso-scale area of steep topography accompanied by a complex differentiation in irradiance and wind field. It is rather obvious that other or additional parameters gain importance at finer scales, while they tend to level off at coarse scales, as found by Xu et al. (2004). For instance, we conducted a series of hand-held measurements on air temperatures at an equally-spaced raster of $20 \mathrm{~m}$ at micro-scale (data not shown), that revealed a differentiation of temperatures dependent on wind exposure. As such, it might be wrong to use the macroscale temperature field at finer scales, as it leads to erroneous results. Thus, an appropriate handling of scaling issues is necessary for temperature modelling, as already proposed by Chave \& Levin (2003) for ecological issues. However, such appropriate handling is hampered by the lack of observations at finer spatial scales, a fact that leads us back to the starting point of the whole discussion about temperature interpolation and modelling: without climatological reference data from spatial scales important for ecological applications - i.e. the meso- and micro-scale-an appropriate estimation of temperature patterns remains difficult.

Acknowledgements. We appreciate the permission to conduct research given by the Norwegian authorities, locals and landowners in Stranda and Vågå communes. We thank B. Schmid for field assistance. We are grateful to Dr. K. Isaksen of the Norwegian Meteorological Service for providing the temperature data from the Geiranger area. Color Line AS, Oslo, kindly supported the study. A research grant to R.P. was provided by the German Academic Exchange Service (DAAD). Comments by 2 reviewers improved the manuscript significantly.

\section{LITERATURE CITED}

Barry RG (2008) Mountain weather and climate. Cambridge University Press, Cambridge

Bello R, Smith JD (1990) The effect of weather variability on the energy balance of a lake in the Hudson Bay lowlands, Canada. Arct Alp Res 22:98-107

Beniston M, Diaz HF, Bradley RS (1997) Climatic change at high elevation sites: an overview. Clim Change 36: 233-251

Böhner J (2004) Regionalisierung bodenrelevanter Klimaparameter für das Niedersächsische Landesamt für Bodenforschung (NLfB) und die Bundesanstalt für Geowissenschaften und Rohstoffe (BGR). Arbeitshefte Boden 4: $17-66$

Chave J, Levin S (2003) Scale and scaling in ecological and economic systems. Environ Resour Econ 26:527-557

Chen J, Saunders SC, Crow TR, Naiman RJ and others (1999) Microclimate in forest ecosystem and landscape ecology. Bioscience 49:288-297

> Chung U, Yun JI (2004) Solar irradiance-corrected spatial interpolation of hourly air temperature in complex terrain. Agric For Meteorol 126:129-139

$>$ Chung U, Seo HH, Hwang KH, Hwang BS, Choie J, Lee JT, Yun JI (2006) Minimum temperature mapping over complex terrain by estimating cold air accumulation potential. Agric For Meteorol 137:15-24

Dahl E (1998) The phytogeography of northern Europe (British Isles, Fennoscandia and adjacent areas). Cambridge University Press, Cambridge

de Bruin HAR, Holtslag AAM (1982) A simple parameterization of the surface fluxes of sensible and latent heat during daytime compared with the Penman-Monteith concept. J Appl Meteorol 21:1610-1621

de Rooy WC, Holtslag AAM (1999) Estimation of surface radiation and energy flux densities from single-level weather data. J Appl Meteorol 38:526-540

Dirnböck T, Dullinger S, Grabherr G (2003) A regional impact assessment of climate and land-use change on alpine vegetation. J Biogeogr 30:401-417

Engstrom RN, Hope AS, Stow DA, Vourlitis GL, Oechel WC (2002) Priestley-Taylor alpha coefficient: variability and relationship to NDVI in Arctic tundra landscapes. J Am Water Resour Assoc 38:1647-1659

Gjærevoll O (1990) Alpine plants. In: Berg RY, Fægri K, Gjærevoll O (eds) Maps of distribution of Norwegian vascular plants, Vol. II. Tapir, Trondheim

Grytnes JA (2003) Species-richness patterns of vascular plants along seven altitudinal transects in Norway. Ecography 26:291-300

Hofierka J, Suri M (2002) The solar radiation model for Open source GIS: implementation and applications. In: Ciolli M, Zatelli P (eds) Proc Open Source Free Software GIS GRASS users conference 2002, Trento, Italy, 11-13 September 2002

Hutchinson MF (1991) The application of thin plate smoothing splines to continent-wide data assimilation. In: Jasper JD (ed) Data assimilation systems. BMRC Research Report No. 27:104-113.

Jacobsen A, Hansen BU (1999) Estimation of the soil heat flux/net radiation ratio based on spectral vegetation indexes in high-latitude Arctic areas. Int J Remote Sens 20:445-461

Jarvis CH, Stuart N (2001) A comparison among strategies for interpolating maximum and minimum daily air temperatures. I. The selection of 'guiding' topographic and land cover variables. J Appl Meteorol 40:1060-1074

Joly D, Brossard T (2007) Contribution of environmental 
factors to temperature distribution at different resolution levels on the forefield of the Loven Glaciers, Svalbard. Polar Rec (Gr Brit) 43:353-359

Joly D, Nilsen L, Fury R, Elvebakk A, Brossard T (2003) Temperature interpolation at a large scale; test on a small area in Svalbard. Int J Climatol 23:1637-1654

Körner C (2003) Alpine plant life: functional plant ecology of high mountain ecosystems. Springer, Berlin

Kustas WP, Daughtry CST (1990) Estimation of the soil heat flux/net radiation ratio from spectral data. Agric For Meteorol 49:205-223

Leser H (1997) Landschaftsökologie. UTB, Stuttgart

> Liebethal C, Foken T (2007) Evaluation of six parameterization approaches for the ground heat flux. Theor Appl Climatol 88:43-56

Löffler J (2002) Altitudinal changes of ecosystem dynamics in the central Norwegian high mountains. Erde 133:227-258

> Löffler J (2003) Micro-climatic determination of vegetation patterns along topographical, altitudinal, and oceaniccontinental gradients in the high mountains of Norway. Erdkunde 57:232-249

Löffler J (2005) Snow cover dynamics, soil moisture variability and vegetation ecology in high mountain catchments of central Norway. Hydrol Process 19:2385-2405

Löffler J, Finch OD (2005) Spatio-temporal gradients between high mountain ecosystems of central Norway. Arct Antarct Alp Res 37:499-513

Löffler J, Pape R (2004) Across-scale temperature modelling using a simple approach for the characterization of high mountain ecosystem complexity. Erdkunde 58:331-348

Löffler J, Pape R (2008) Diversity patterns in relation to the environment in alpine tundra ecosystems of northern Norway. Arct Antarct Alp Res 40:373-381

Löffler J, Pape R, Wundram D (2006) The climatologic significance of topography, altitude and region in high mountains - a survey of oceanic-continental differentiations of the Scandes. Erdkunde 60:15-24

Lookingbill TR, Urban DL (2003) Spatial estimation of air temperature differences for landscape-scale studies in montane environments. Agric For Meteorol 114:141-151

Mendez J, Hinzman LD, Kane DL (1998) Evapotranspiration from a wetland complex on the arctic coastal plain of Alaska. Nord Hydrol 29:303-330

Moen A (1999) National atlas of Norway: vegetation. Norwegian Mapping Authority, Hønefoss

- Monestiez P, Courault D, Allard D, Ruget F (2001) Spatial interpolation of air temperature using environmental context: application to a crop model. Environ Ecol Stat 8: 297-309

> Monteith JL (1981) Evaporation and surface temperature. Q J R Meteorol Soc 107:1-27

> Mostovoy GV, King RL, Reddy KR, Kakani VG, Filippova MG (2006) Statistical estimation of daily maximum and minimum air temperatures from MODIS LST data over the state of Mississippi. GIScience Remote Sens 43:78-110

Oke TR (2001) Boundary layer climates. Routledge, London

Ostendorf B, Reynolds JF (1993) Relationships between a terrain-based hydrologic model and patch-scale vegetation patterns in an arctic tundra landscape. Landscape Ecol 8:229-237

Pape R, Löffler J (2004) Modelling spatio-temporal near-surface temperature variation in high mountain landscapes. Ecol Model 178:483-501

Pauli H, Gottfried M, Hohenwallner D, Hülber K, Reiter K,

Editorial responsibility: Gerd Esser,

Gießen, Germany
Grabherr G (2001) The multi-summit approach—global observation research initiative in alpine environments. Field manual, third version. GLORIA, Vienna

> Priestley CHB, Taylor RJ (1972) On the assessment of surface heat flux and evaporation using large-scale parameters. Mon Weather Rev 100:81-92

Rissanen P, Jacobsson C, Madsen H, Moe M, Pálsdóttir P, Vejen F (2000) Nordic methods for quality control of climate data. Report 10/00, DNMI Oslo

Rivington M, Miller D, Matthews KB, Russell G, Bellocchi G, Buchan K (2008) Downscaling regional climate model estimates of daily precipitation, temperature and solar radiation data. Clim Res 35:181-202

Rolland C (2003) Spatial and seasonal variations of air temperature lapse rates in alpine regions. J Clim 16:1032-1046

Roulet NT, Woo M (1986) Hydrology of a wetland in the continuous permafrost region. J Hydrol (Amst) 89:73-91

Rouse WR, Stewart RB (1972) A simple model for determining the evaporation from high latitude upland sites. J Appl Meteorol 11:1063-1070

> Rouse WR, Mills PF, Stewart RB (1977) Evaporation in high latitudes. Water Resour Res 13:909-914

Rovansek RJ, Hinzman LD, Kane DL (1996) Hydrology of a tundra wetland complex on the Alaskan arctic coastal plain, USA. Arct Alp Res 28:311-317

Saunders IR, Bowers JD, Huo Z, Bailey WG, Verseghy DL (1999a) Simulation of alpine tundra surface microclimates using CLASS. I. Albedo and net radiation modelling. Int J Climatol 19:913-926

Saunders IR, Bowers JD, Huo Z, Bailey WG, Verseghy DL (1999b) Simulation of alpine tundra surface climates using CLASS. II. Energy balance and surface microclimatology. Int J Climatol 19:1131-1143

Stahl K, Moore RD, Floyer JA, Asplin MG, McKendry IG (2006) Comparison of approaches for spatial interpolation of daily air temperature in a large region with complex topography and highly variable station density. Agric For Meteorol 139:224-236

Stewart RB, Rouse WR (1976) Simple models for calculating evaporation from dry and wet tundra surfaces. Arct Alp Res 8:263-274

Sulebak JR, Tallaksen LM, Erichsen B (2000) Estimation of areal soil moisture by use of terrain data. Geogr Ann 82: 89-105

- Theurillat JP, Guisan A (2001) Potential impact of climate change on vegetation in the European Alps: a review. Clim Change 50:77-109

> van Ulden AP, Holtslag AAM (1985) Estimation of atmospheric boundary layer parameters for diffusion applications. J Clim Appl Meteorol 24:1196-1207

Wang T, Hamann A, Spittlehouse DL, Aitken SN (2006) Development of scale-free climate data for Western Canada for use in resource management. Int J Climatol 26:383-397

Whittaker RH (1978) Ordination of plant communities. Handbook of vegetation science, Vol. 5. Junk, The Hague

Wielgolaski FE (ed) (1998) Polar and alpine tundra. Ecosystems of the world 3. Elsevier, Amsterdam

Wundram D, Löffler J (2008) High resolution spatial analysis of mountain landscapes using a low altitude remote sensing approach. Int J Remote Sens 29:961-974

Xu M, Qi Y, Chen J, Song B (2004) Scale-dependent relationships between landscape structure and microclimate. Plant Ecol 173:39-57

Submitted: April 7, 2008; Accepted: March 3, 2009

Proofs received from author(s): May 29, 2009 